\title{
A novel leukocyte adhesion deficiency caused by expressed but nonfunctional $\beta 2$ integrins Mac-1 and LFA-1
}

\author{
Nancy Hogg, ${ }^{1}$ Mairi P. Stewart, ${ }^{1}$ Sarah L. Scarth, ${ }^{2}$ Rebecca Newton, ${ }^{1}$ Jacqueline M. Shaw, ${ }^{2}$ \\ S.K. Alex Law, ${ }^{2}$ and Nigel Klein ${ }^{3}$ \\ ${ }^{1}$ Leukocyte Adhesion Laboratory, Imperial Cancer Research Fund, London WC2A 3PX, United Kingdom \\ ${ }^{2}$ The MRC Immunochemistry Unit, Department of Biochemistry, University of Oxford, OX1 3QU Oxford, United Kingdom \\ ${ }^{3}$ Immunobiology Unit, Institute of Child Health, 30 Guilford Street, London WC1N 1EH, United Kingdom \\ Address correspondence to: Nancy Hogg, Leukocyte Adhesion Laboratory, Imperial Cancer Research Fund, Lincoln's Inn Fields, \\ London WC2A 3PX, United Kingdom. Phone: 44-171-269-3255; Fax: 44-171-269-3093; E-mail: hogg@icrf.icnet.uk \\ Received for publication March 5, 1998, and accepted in revised form November 18, 1998.
}

In the leukocyte adhesion deficiency (LAD)- 1 syndrome, there is diminished expression of $\beta 2(\mathrm{CD} 18)$ integrins. This is caused by lesions in the $\beta 2$-subunit gene and gives rise to recurrent bacterial infections, impaired pus formation, and poor wound healing. We describe a patient with clinical features compatible with a moderately severe phenotype of LAD- 1 but who expresses the $\beta 2$ integrins lymphocyte function- associated molecule (LFA)- 1 and Mac- 1 at $40 \%-60 \%$ of normal levels. This level of expression should be adequate for normal integrin function, but both the patient's Mac-1 on neutrophils and LFA-1 on T cells failed to bind ligands such as fibrinogen and intercellular adhesion molecule (ICAM)-1, respectively, or to display a $\beta 2$-integrin activation epitope after adhesion-inducing stimuli. Unexpectedly, divalent cation treatment induced the patient's T cells to bind to ICAM-2 and ICAM-3. Sequencing of the patient's two CD18 alleles revealed the mutations S138P and G273R. Both mutations are in the $\beta 2$-subunit conserved domain, with $\mathrm{S} 138 \mathrm{P}$ a putative divalent cation coordinating residue in the metal ion-dependent adhesion site (MIDAS) motif. After K562 cell transfection with $\alpha$ subunits, the mutated S138P $\beta$ subunit was coexpressed but did not support function, whereas the G273R mutant was not expressed. In summary, the patient described here exhibits failure of the $\beta 2$ integrins to function despite adequate levels of cell-surface expression.

J. Clin. Invest. 103:97-106 (1999).

\section{Introduction}

The adhesive response of circulating leukocytes to inflammatory stimuli is now well documented $(1,2)$. After such signals, leukocytes adhere to the blood vasculature using selectin-mediated interactions, and this stage leads to activation of their integrins. The $\beta 2$ or leukocyte integrins lymphocyte function-associated molecule (LFA)-1 (CD11a/CD18) has a major role in the firm adhesion of leukocytes to endothelium and in their migration across this barrier. In addition, LFA-1 cooperates with the T-cell receptor in antigen-stimulated T-cell priming (3) and, in general, participates in the formation of leukocyte-leukocyte contacts. Mac-1 (CD11b/CD18) is a major phagocytic receptor operating in association with the third $\beta 2$ integrin, $\mathrm{p} 150,95$ (CD11c/CD18), and both recognize as ligands fibrinogen and the complement fragment iC3b $(4,5)$.

Expression of integrins on the cell membrane is not a guarantee of their ability to function as adhesion receptors. Integrins must undergo conversion from inactive to active ligand-binding status, which occurs through a process of clustering and/or altered conformation $(6,7)$. The stimulus for this activation is initiated by the triggering of other membrane receptors, a route of signal transduction that has been termed "inside out" signaling. The integrins bind divalent cations such as $\mathrm{Mg}^{2+}$ or $\mathrm{Mn}^{2+}$ in order to function, and an alternative means of directly altering integrin activity is through extracellular exposure to these cations. It is thought that these latter procedures mimic the conformational changes brought about by integrin-activating signals generated intracellularly. Special anti-integrin monoclonal antibodies (MABs) can serve as reporters of this activation. For example, MAB 24 recognizes an epitope on high-affinity $\beta 2$ integrin (7) and detects a conformational change in the form of interdomain movement involving the ligand binding I domain on the integrin $\alpha$ subunit (8).

Valuable information about the functioning of the $\beta 2$ integrins has come from study of the leukocyte adhesion deficiency (LAD)-1 syndrome. LAD-1 is an autosomal recessive disorder caused by mutation in the CD18 gene on chromosome 21 that leads to absent or aberrant biosynthesis of the $\beta 2$ subunit of leukocyte integrins (9-11). This lesion is reflected in the absence or markedly diminished expression on the leukocyte cell surface of the $\beta 2$ integrins, CD11a/CD18 (LFA-1), CD11b/CD18 (Mac-1), and CD11c/CD18 (p150,95). The patient phenotype is variable but reflects the level of $\beta 2$ integrins expressed. Patients with $<1 \%$ expression suffer from life-threatening infections and require bone marrow transplantation for long-term survival (12). In patients with $1 \%-10 \%$ expression, defects in leukocyte mobility, adherence, and endocytosis lead to periodic periodontitis, skin infections, and retarded wound healing with dysplastic scarring. The heterozygotic relatives of the patients have $40 \%-60 \%$ normal levels of $\beta 2$ inte- 
Table 1

Comparison of membrane receptors on control versus LAD-1 T cells T cell fluorescence (MFI)

Membrane receptor (MAB)

Control

Control

Patient

$\beta 2$ integrins

CD18 (H52)

CD11a (38)

CD11b (ICRF44)

CD11c (3.9)

Other adhesion molecules

CD29 (TS2/16)

CD54 (15.2)

CD50 (CAL 3.10)

Other receptors

CD3 (UCHT1)

CD4 (QS4120)

CD8 (14)

CD45RO (UCHL1)

$3.58 \quad 3.49$

756.89

625.58

12.72

3.95

227.15

57.38

355.61

510.69

557.09

520.62

207.95

275.60

208.29

3.51

3.15

184.96

45.25

363.22

495.29

589.73

430.32

191.60
Flow cytometric analysis of patient and control $\mathrm{T}$ cells comparing membrane expression levels of LFA-1 and other T cell-specific membrane receptors. LAD, leukocyte adhesion deficiency; $M F I$, mean fluorescence intensity (units); $M A B$, monoclonal antibody.

grins and are clinically normal (9).

We have identified an unusual patient with $\beta 2$ - integrin expression that resembles that of LAD-1 heterozygotes but with a failure of integrin function and lack of expression of the MAB 24 activation epitope. The Mac-1 integrin on stimulated neutrophils was unable to adhere to ligands such as fibrinogen or to participate in bacterial phagocytosis. LFA- 1 on $T$ cells from this patient was unable to recognize its principal ligand, intercellular adhesion molecule (ICAM)-1. The adhesion deficiencies of this patient have provided insight into the functioning of $\beta 2$ integrins and demonstrated that an LAD syndrome can exist when levels of $\beta 2$ - integrin expression should be compatible with normal function.

\section{Methods}

Monoclonal antibodies. MABs used in this study from the authors' laboratories are 38 (CD11a), ICRF44 (CD11b), 3.9 (CD11c), H52 (CD18), 1B4 (CD18), 15.2 (CD54), and MAB 24, directed against an activation reporter epitope on $\beta 2$ integrins (13), QS4120 (CD4) MAB 14 (CD8), and control MAB 52U. Other MABs were kind gifts as follows: CD11a MAB DF1524 from D. Flavell (Southampton General Hospital, Southampton, United Kingdom); CD18 MABs KIM 127 and KIM 185 from M. Robinson (CellTech, Slough, United Kingdom); MAB 60.3 from BristolMyers Squibb Co. (Seattle, Washington, USA); TS2/16 (CD29) and HP1/2 (CD49d) from R. Lobb (Biogen Inc., Cambridge, Massachusetts, USA; HUTS 21 (CD29) directed against an activation reporter epitope on $\beta 1$ integrins (14) from C. Cabanas (Universidad Complutense, Madrid, Spain); CAL 3.10 (CD50) from D. Simmons (Imperial Cancer Research Fund, Oxford, United Kingdom); UCHT1 (CD3) and UCHL1 (CD45RO) from P. Beverley (University College, London, United Kingdom); MHM24 from A. McMichael (Institute of Molecular Medicine, Oxford, United Kingdom); LPM19c from K. Pulford LRF Diagnostic Unit (Oxford, United Kingdom); and control MAB OX34 from the MRC Cellular Immunology Unit (University of Oxford, Oxford, United Kingdom). Additional CD11 and CD18 MABs were from the Fifth Leukocyte Typing Workshop (Boston, Massachusetts, USA, 1993). Phycoerythrin-conjugated CD18 MAB L130 was purchased from Becton Dickinson UK Ltd. (Oxford, United Kingdom). SAM-1 (CD49e) was purchased from Eurogenetics (Hampton, United Kingdom). Unless otherwise specified, all MABs were purified and used at $10 \mu \mathrm{g} / \mathrm{ml}$.

Preparation of neutrophils and T cells from the patient and controls. Neutrophils were isolated from heparin-anticoagulated venous blood obtained from the patient and age-matched controls by dextran sedimentation and Percoll density gradient centrifugation (15). The neutrophils were removed and washed in HBSS containing $1 \mathrm{mM} \mathrm{Ca}^{2+}, 1 \mathrm{mM} \mathrm{Mg}^{2+}, 0.1 \% \mathrm{wt} / \mathrm{vol}$ glucose, and $10 \mathrm{mM}$ HEPES (H-HBSS), and resuspended at $5 \times 10^{6} / \mathrm{ml}$. The neutrophils were $>95 \%$ pure and $>99 \%$ viable.

Mononuclear cells were obtained from the peripheral blood by centrifugation over Lymphoprep (Nycomed, [U.K.] Ltd., Birmingham, United Kingdom) T lymphoblasts were expanded from these populations by initial activation with $1 \mu \mathrm{g} / \mathrm{ml}$ phytohaemagglutinin (Murex Diagnostics Ltd., Dartford, United Kingdom) for 4 days at $37^{\circ} \mathrm{C}$ in Roswell Park Memorial Institute medium (RPMI) with $10 \% \mathrm{FCS}$, as described previously (16). Cells were then maintained in culture with $20 \mathrm{ng} / \mathrm{ml}$ rIL-2 (Cetus Corp., Berkeley, California, USA) and used between days 10 and 14 of culture.

Flow cytometric analysis of leukocyte adhesion molecule expression. Purified neutrophils and T cells $\left(\sim 5 \times 10^{5}\right.$ cells in $\left.50 \mu \mathrm{l}\right)$ were incubated with MABs for $30 \mathrm{~min}$ at room temperature or MAB 24 at $37^{\circ} \mathrm{C}$ in $\mathrm{H}$-HBSS as described previously $(17,18)$. The cells were washed in FACSwash (PBS with $0.2 \% \mathrm{wt} / \mathrm{vol}$ BSA, 0.1\% $\mathrm{wt} / \mathrm{vol}$ sodium azide) and resuspended in FACSwash containing 1:200 diluted FITC-conjugated goat anti-mouse IgG (Sigma Chemical Co., Poole, United Kingdom). After $30 \mathrm{~min}$ on ice, the cells were again washed, resuspended in $200 \mu \mathrm{l}$ FACSwash, and analyzed using the FACScan BBecton Dickinson [Europe], Meylan, France). K562 transfectants were similarly analyzed. Alternatively, $50-\mu \mathrm{l}$ samples of blood were incubated for $15 \mathrm{~min}$ with $5 \mu$ of phycoerythrin-conjugated MAB L130 (CD18), and the rest of the procedure was carried out as described previously (19). Leukocytes were incubated at $37^{\circ} \mathrm{C}$ with FITC-conjugated MAB 24 in whole blood using a similar method.

Neutrophil adhesion assay. Maxisorp Immuno-plates (96-well; GIBCO BRL, Paisley, Scotland) were coated overnight at $4{ }^{\circ} \mathrm{C}$ with $50 \mu \mathrm{l}$ of fibrinogen (Sigma Chemical Co., Dorset, United Kingdom) at $2 \mathrm{mg} / \mathrm{ml}$ in $0.1 \mathrm{M}$ carbonate buffer, $\mathrm{pH} 9.5$, and then washed two times in H-HBSS suspension buffer. Purified neutrophils $\left(5 \times 10^{6} / \mathrm{ml}\right)$ were labeled with $1 \mu \mathrm{M} 2^{\prime}, 7^{\prime}$-bis- $(2$-carboxyethyl)-5-(and-6)-carboxyfluorescein-acetoxymethyl ester (BCECF; Calbiochem-Novabiochem UK Ltd., Nottingham, United Kingdom) for $30 \mathrm{~min}$ at room temperature (20). After washing, $50 \mu \mathrm{l}$ of cells $\left(2 \times 10^{6} / \mathrm{ml}\right)$ were added to appropriate wells together with $50 \mu \mathrm{l}$ of either H-HBSS alone or H-HBSS containing $2 \times 10^{-7} \mathrm{M}$ FMLP. After $30 \mathrm{~min}$ at room temperature, the plates were washed, and adhering neutrophils were quantified using a fluorescence microtiter plate reader (Fluoroskan II; Labsystems, Basingstoke, United Kingdom).

T-cell adhesion assay. A construct encoding the five extracellular domains of human ICAM-1 fused to the Fc portion of human IgG1 (ICAM-1/Fc) was prepared as described previously (21). ICAM-2/Fc and ICAM-3/Fc (gift from D. Simmons, Imperial Cancer Research Fund, Oxford, United Kingdom) were similarly prepared. Flat-bottomed 96-well Immulon 1 plates (Dynatech Laboratories Ltd., Billinghurst, United Kingdom) were precoated with $50 \mu \mathrm{l}$ of ICAM-1/Fc $(0.24 \mu \mathrm{g} /$ well $)$, ICAM-2/Fc $(0.5 \mu \mathrm{g} /$ well $)$, and ICAM-3/Fc $(1 \mu \mathrm{g} /$ well $)$ in PBS overnight at $4{ }^{\circ} \mathrm{C}$, blocked with $2.5 \%$ (wt/vol) BSA in PBS for 1 $h$ at room temperature, and then washed four times in PBS and 
a

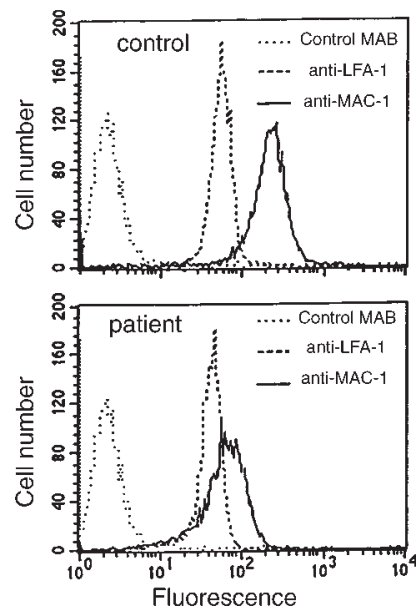

$\boldsymbol{b}$

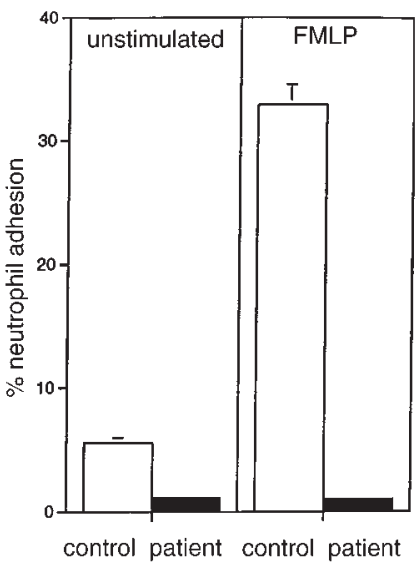

C

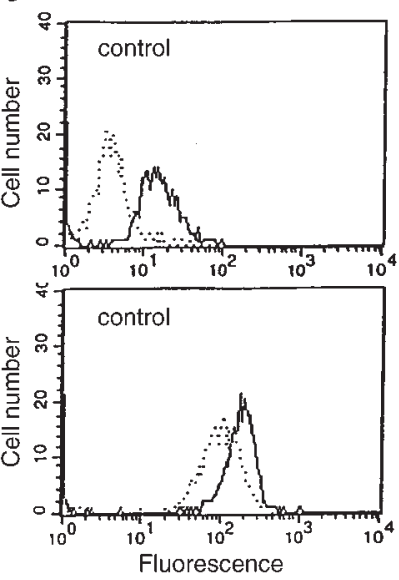

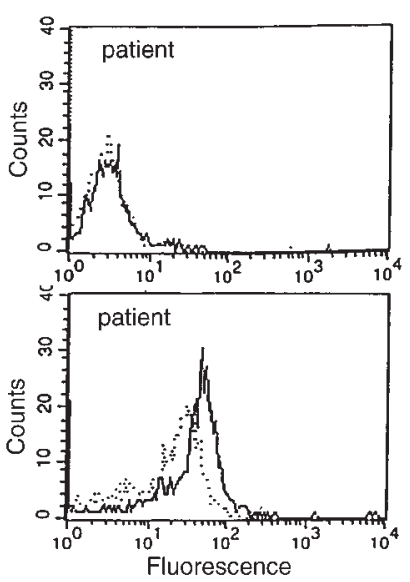

Figure 1

Comparison of patient and control neutrophil $\beta 2$ integrins. (a) Expression of cell membrane levels of Mac-1 (CD11b/CD18) and LFA-1 (CD11a/CD18). (b) Assay of neutrophil Mac-1 function: Ability of control (white bars) and patient (black bars) neutrophils to bind to immobilized ligand fibrinogen with and without exposure to $0.1 \mu \mathrm{M}$ FMLP. (c) Ability of patient and control neutrophils to respond to external stimuli. Control, but not patient, neutrophils are able to express the $\beta 2$-integrin activation reporter epitope recognized by MAB 24 , indicative of active $\beta 2$ integrins (top panels). Both patient and control neutrophils can upregulate Mac-1 (bottom panels) after exposure to $0.1 \mu \mathrm{M} \mathrm{FMLP}$ (dotted lines, -FMLP; solid lines, +FMLP), indicating that the patient cells have a normal response to external stimuli. LFA, lymphocyte function-associated molecule; MAB, monoclonal antibody.

twice in $20 \mathrm{mM}$ HEPES, $140 \mathrm{mM} \mathrm{NaCl}, 2 \mathrm{mg} / \mathrm{ml}$ glucose, $\mathrm{pH}$ 7.4 (HEPES/ $\mathrm{NaCl}$ buffer). A total of $5 \times 10^{7}$ cultured $\mathrm{T}$ cells were labeled with $25 \mu \mathrm{Ci}$ of $\left[{ }^{3} \mathrm{H}\right]$ thymidine overnight at $37^{\circ} \mathrm{C}$ and then washed three times in HEPES/NaCl buffer. On ICAM/Fc-coated wells, $50 \mu \mathrm{l}$ of T-cell suspension $\left(5 \times 10^{6}\right.$ cells $/ \mathrm{ml}$ ) was combined with $50 \mu$ l of HEPES/ $\mathrm{NaCl}$ buffer containing at two-times concentration $10 \mathrm{mM} \mathrm{MgCl} / 2 \mathrm{mM}$ EGTA $\left(\mathrm{Mg}^{2+} /\right.$ EGTA), $1 \mathrm{mM} \mathrm{Mn}{ }^{2+}, 1 \mathrm{mM}$ EDTA, or $100 \mathrm{nM}$ phorbol12,13-dibutyrate (PDBu; Calbiochem-Novabiochem UK Ltd.). Other integrin-activating protocols included treatment of $\mathrm{T}$ cells in RPMI- 1640 with MAB UCHT1 at $10 \mu \mathrm{g} / \mathrm{ml}$, CD18-activating MABs KIM 127 or KIM 185 at $20 \mu \mathrm{g} / \mathrm{ml}$, and CD29 MAB TS2 $/ 16$ at $10 \mu \mathrm{g} / \mathrm{ml}$ as described previously (18). Alternatively, cells were preincubated at $37^{\circ} \mathrm{C}$ with $5 \mu \mathrm{M} \mathrm{Ca}^{2+}$ mobilizer thapsigargin (Calbiochem-Novabiochem UK Ltd.) (22). The assay was then performed exactly as described previously $(18,22)$.

\section{Sequence analysis of the CD18-subunit alleles}

$m R N A$ and $c D N A$ preparation. PolyA RNA was obtained from Epstein-Barr virus (EBV)-transformed cells of patient JT (JTEBV) using the Quickprep Micro mRNA purification kit (Pharmacia Biotech, St. Albans, United Kingdom). The resulting mRNA was used to make cDNA with the Reverse Transcription Kit (Promega Corp., Southampton, United Kingdom). The CD18 cDNA was first amplified with oligonucleotides flanking the coding region (K88/16 and A87/20) using the Expand High Fidelity PCR System (Boehringer Mannheim, East Sussex, United Kingdom). Two overlapping fragments were amplified with the pfu polymerase (Stratagene Ltd., Cambridge, United Kingdom): A (“-73" to "968") using the oligonucleotides A87/19 and A89/14, and B (" 860 " to "2400") using the oligonucleotides K89/17 and F89/11. These fragments were cloned into pBluescript using the pCR-Script Amp SK $(+)$ cloning kit (Stratagene Ltd.). DNA sequencing was performed using reagents in the ${ }^{\mathrm{T} 7}$ Sequencing Kit (Pharmacia Biotech) on double-strand templates with appropriate primers.

Amplification and cloning of genomic DNA fragments. Genomic DNA from JT-EBV-transformed cells was prepared as described previously (23). The region containing the S138P mutation in exon-5 was amplified using nested PCR (24), with the first rounds using oligonucleotides C93/17 and C93/18, and the second rounds using oligonucleotides K89/16 and $\mathrm{E} 90 / 22$. The region containing the G273R mutation in exon7 was similarly amplified using the oligonucleotide pairs I67 and I78, and E94/04 and E94/03 (24). The PCR fragments were cloned and sequenced.

Oligonucleotides. The sequences of the oligonucleotides are A87/19, CCAGGGCAGACTGGTAGCAAAGCC; I67, GAAACTGAGGCAGGTAACC; I78, GCTCTGTCAGGTGGAGACC; E94/03, TCAGTGGTGTCCTGCCAG; and E94/04, TGCTGGTGTTTGCCACTG. All other oligonucleotides were described previously (25).

Expression of CD11/CD18 antigens and adhesion assay using K562 transfectants. Both the S138P and G273R mutations are within a BamHI-EcoRI fragment of the CD18 cDNA. The fragments carrying the mutations were gel purified with the QIAquick Gel Extraction kit (QIAGEN Ltd., Crawley, United Kingdom) and exchanged into the normal CD18 CDNA in the expression vector pcDNA3 (Invitrogen BV, Leek, the Netherlands). cDNA clones for CD11a and CD11b have been described previously (26). K562 were grown in RPMI-1640 with $10 \%$ FCS (RPMI/FCS) to log phase and resuspended in serum-free RPMI1640 at $\sim 1 \times 10^{7} / \mathrm{ml}$. A total of $0.5 \mathrm{ml}$ of cells was transferred into a $0.4-\mathrm{cm}$ cuvette, and $40 \mu \mathrm{g}$ of CD11 cDNA and $10 \mu \mathrm{g}$ of CD18 cDNA were added. Electroporation was carried out at $960 \mu \mathrm{F}$ and $320 \mathrm{~V}$ (Gene Pulser; Bio-Rad Laboratories Ltd., Hemel Hempsted, United Kingdom) K562 transfectants were allowed to recover in RPMI with $10 \%$ FCS at $\sim 2 \times 10^{5} / \mathrm{ml}$ after electroporation for $24 \mathrm{~h}$ at $37^{\circ} \mathrm{C}$ in $5 \% \mathrm{CO}_{2}$ incubator. Surface expression of CD11/CD18 antigens was analyzed by flow cytometry as described for $\mathrm{T}$ cells and neutrophils.

Cell-adhesion assay. A total of $25 \mathrm{ml}$ of cells was spun down, resuspended in $3 \mathrm{ml}$ of RPMI with 5\% FCS, $10 \mathrm{mM}$ HEPES, pH 7.5 , and labeled by adding $5 \mu \mathrm{l} \mathrm{BCECF}(1 \mu \mathrm{g} / \mathrm{ml}$ in DMSO $)$ for $30 \mathrm{~min}$ at $37^{\circ} \mathrm{C}$. The cells were washed twice in RPMI/FCS/HEPES and resuspended in $2.5 \mathrm{ml}$ together with final concentrations of activating MAB KIM 185 or blocking 
MABs (either CD11a MAB MHM24 or CD11b MAB 2LPM19c at $10 \mu \mathrm{g} / \mathrm{ml})$ and $5 \mathrm{mM} \mathrm{Mg} / 1 \mathrm{mM}$ EGTA. Next, $50 \mu \mathrm{l}$ of the cell suspension was delivered into each microtiter well precoated with ligands and was incubated at $37^{\circ} \mathrm{C}$ for $30 \mathrm{~min}$. The cells were washed three times with $150 \mu \mathrm{l}$ of RPMI/FCS/HEPES, and the number of cells that remained bound was determined using a fluoroscent plate reader (Cytofluor 4000; PerSeptive Biosystems, Framingham, Massachusetts, USA). Total cells in each well were quantitated before washing.

ICAM coating. A total of $100 \mu \mathrm{l}$ of anti-human IgG (Fc specific) at $5 \mu \mathrm{g} / \mathrm{ml}$ in $50 \mathrm{mM}$ sodium-bicarbonate, $\mathrm{pH}$ 9.0, was coated onto each microtiter well for $4 \mathrm{~h}$ at room temperature followed by incubation at $4^{\circ} \mathrm{C}$ overnight. The wells were washed once with $150 \mu \mathrm{l}$ PBS and blocked with $150 \mu \mathrm{l}$ of $0.5 \%$ (wt/vol) BSA in PBS at $37^{\circ} \mathrm{C}$ for $45 \mathrm{~min}$. Next, $50 \mu \mathrm{l}$ of ICAM $/ \mathrm{Fc}(1,2$, or 3 ) at $1 \mu \mathrm{g} / \mathrm{ml}$ in $0.1 \%$ (wt/vol) BSA in PBS was added to each well.

$i C 3 b$ and BSA coating. A total of $100 \mu \mathrm{l}$ of $\mathrm{iC} 3 \mathrm{~b}$, a kind gift of A.W. Dodds and R.B. Sim (University of Oxford, Oxford, United Kingdom), at $7.5 \mu \mathrm{g} / \mathrm{ml}$ and BSA at $50 \mu \mathrm{g} / \mathrm{ml}$ in $50 \mathrm{mM}$ sodium-bicarbonate was coated for $4 \mathrm{~h}$ at room temperature followed by incubation at $4{ }^{\circ} \mathrm{C}$ overnight. After washing once with $150 \mu \mathrm{l}$ PBS, the wells were blocked with $300 \mu \mathrm{l}$ of $0.2 \%$ (wt/vol) polyvinylpyrrolidone (average $\mathrm{mol} \mathrm{wt}=10,000$; Sigma Chemical Co.) in PBS at room temperature for 2 to $3 \mathrm{~h}$. The wells were washed twice with $150 \mu \mathrm{l}$ of RPMI/FCS/HEPES before use.

\section{Results}

Patient. We describe 15-year-old patient JT, who first presented as an infant with severe and recurrent skin infections requiring prolonged treatment with intravenous antibiotics and surgery to remove necrotic tissue. In spite of attentive oral hygiene, the patient suffered from severe periodontitis and gingivitis. Otitis media and chest infections had also been consistent features of this patient's condition. Organisms isolated from infected sites included Staphylococcus aureus, Pseudomonas, and Streptococcus species.

The neutrophil count was persistently elevated, reaching peaks of $>50 \times 10^{9} / 1$ at times of infection compared with the range of $2-8 \times 10^{9} / 1$ among normal individuals. Phagocytosis by the patient's neutrophils was $<25 \%$ that of a healthy adult control as assessed by internalization of a strain of Staphylococcus epidermidis that was poorly phagocytic in the absence of complement $(n=2)$. Respiratory burst was either normal or slightly enhanced, and intracellular killing of S. epidermidis was within normal

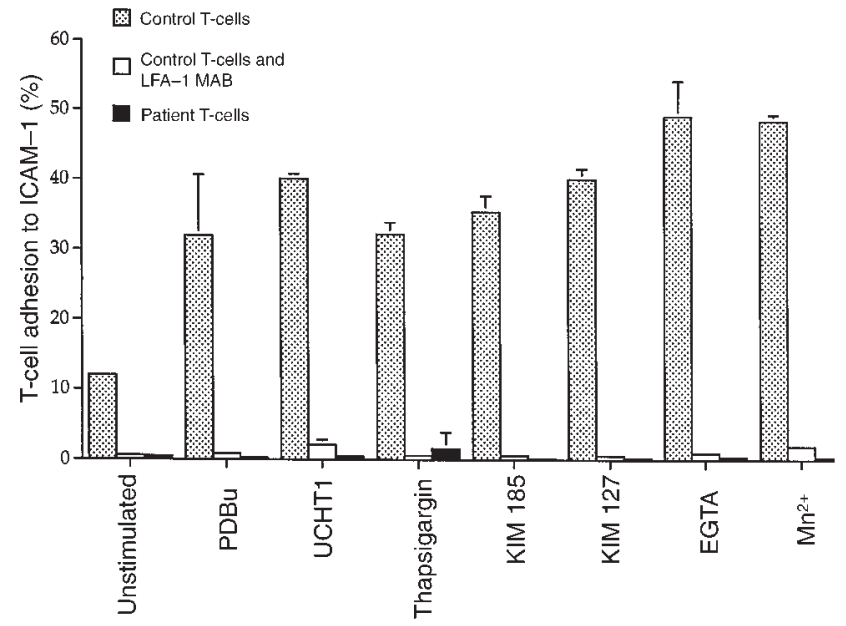

Figure 2

The ability of patient (black bars) and control (dotted bars) T-cell LFA-1 to adhere to immobilized ICAM-1 after activating stimuli (see Methods). Several treatments were used that trigger LFA-1-mediated adhesion by intracellular signaling (PDBu, cross-linking the T-cell receptor with CD3 MAB UCHT1, $\mathrm{Ca}^{2+}$ mobilizer thapsigargin) or by acting extracellularly $\left(\mathrm{Mg}^{2+} /\right.$ EGTA, $\mathrm{Mn}^{2+}$, or $\beta 2$-activating MABs KIM 127 and KIM 185). CD11a MAB 38 inhibited binding of control T cells under all conditions (white bars). ICAM, intercellular adhesion molecule; PDBu, phorbol-12,13 dibutyrate.

limits. Therefore, although the uptake of the organisms was faulty, intracellular processes by which phagocytes deal with bacteria appeared normal.

Lymphocytes were within the normal range of $1.5-4 \times$ $10^{9} / 1$, and T-lymphocyte subsets and mitogen and antigen responses were also within normal limits. There was evidence of lymphocyte activation with increased expression of CD25 and decreased expression of L-selectin on CD4 cells. Immunoglobulin levels, resting nitroblue tetrazolium tests, and C-reactive proteins were elevated, consistent with chronic infection. Bleeding time, platelet count, platelet function, and plasma coagulation parameters were all normal. Put together, these clinical features are typical of LAD-1 classified as moderately severe (9), although separation of the patient's umbilical cord, which is a frequent but not invariant feature of LAD-1, was not delayed. Since 1994 the patient's condition deteriorated, with frequent occurrence of sustained skin

Table 2

Mutations and polymorphisms in patient CD18 alleles

\begin{tabular}{|c|c|c|c|c|}
\hline \multirow[b]{2}{*}{$\begin{array}{l}\text { Mutation/ } \\
\text { polymorphism }\end{array}$} & \multicolumn{2}{|c|}{ cDNA } & \multicolumn{2}{|c|}{ Genomic DNA } \\
\hline & Sequence $^{B}$ & $\begin{array}{l}\text { No. variant clones/ } \\
\text { No. clones sequenced }\end{array}$ & $\begin{array}{l}\text { Exon } \\
\text { location }\end{array}$ & $\begin{array}{l}\text { No. variant clones/ } \\
\text { No. clones sequenced }\end{array}$ \\
\hline S138P & T412C & $6 / 9$ & 5 & $3 / 6$ \\
\hline G273R & G817A & $3 / 9$ & 7 & $3 / 5$ \\
\hline V367V & C1111A & $3 / 9$ & 10 & $N D^{E}$ \\
\hline V441V & C1323T & $6 / 9$ & 11 & ND \\
\hline
\end{tabular}

AMutations and polymorphisms in the CD18 sequence. The initiation methionine is assigned number "1" in the protein sequence. The two point mutations are shown in bold. BMutations in the CDNA sequence. The " $A$ " in the initiation codon " $A T G$ " is assigned number "1." For clarity, the DNA sequences and numbering are shown in italics. "The S138P and G273R mutations are mutually exclusive in nine fragment A (-73 to 968) clones sequenced. Similarly, the V367V and V441V polymorphisms are mutually exclusive in nine fragment B (860 to 2400 ) clones sequenced.

${ }^{\mathrm{D}} \mathrm{Clones}$ in exon-5 and exon-7 not carrying the mutations are normal.

ENot done. 
Table 3

Adhesion of LFA-1 and Mac-1 K562 transfectants to ligands

\begin{tabular}{|c|c|c|c|c|}
\hline \multicolumn{3}{|c|}{ LFA- 1 wild type } & \multicolumn{2}{|c|}{ LFA-1(S138P) } \\
\hline Activation treatment & & $+\mathrm{MHM} 24^{\mathrm{A}}$ & & $+\mathrm{MHM} 24$ \\
\hline \multicolumn{5}{|l|}{ ICAM-1 adhesion } \\
\hline None & $0.6 \pm 0.2$ & $0.1 \pm 0.0$ & $0.1 \pm 0.0$ & $0.1 \pm 0.0$ \\
\hline KIM 185 & $4.5 \pm 0.8$ & $0.7 \pm 0.0$ & $0.1 \pm 0.0$ & $0.0 \pm 0.0$ \\
\hline $\mathrm{Mg} / \mathrm{EGTA}$ & $20.9 \pm 1.1$ & $0.1 \pm 0.0$ & $0.1 \pm 0.0$ & $0.1 \pm 0.0$ \\
\hline KIM $185+$ Mg/EGTA & $40.5 \pm 2.9$ & $0.1 \pm 0.0$ & $0.1 \pm 0.0$ & $0.0 \pm 0.0$ \\
\hline \multicolumn{5}{|l|}{ ICAM-2 adhesion } \\
\hline None & $0.5 \pm 0.1$ & $0.1 \pm 0.0$ & $0.4 \pm 0.3$ & $0.1 \pm 0.0$ \\
\hline KIM 185 & $0.1 \pm 0.0$ & $0.1 \pm 0.0$ & $0.1 \pm 0.0$ & $0.0 \pm 0.0$ \\
\hline Mg/EGTA & $1.5 \pm 0.1$ & $0.1 \pm 0.0$ & $0.3 \pm 0.1$ & $0.1 \pm 0.0$ \\
\hline KIM $185+$ Mg/EGTA & $3.3 \pm 0.3$ & $0.1 \pm 0.0$ & $0.1 \pm 0.0$ & $0.1 \pm 0.0$ \\
\hline \multicolumn{5}{|l|}{ ICAM-3 adhesion } \\
\hline None & $0.5 \pm 0.2$ & $0.1 \pm 0.0$ & $0.3 \pm 0.1$ & $0.1 \pm 0.0$ \\
\hline KIM 185 & $0.1 \pm 0.0$ & $0.0 \pm 0.0$ & $0.1 \pm 0.0$ & $0.0 \pm 0.0$ \\
\hline $\mathrm{M} \mathrm{g} / \mathrm{EGTA}$ & $0.7 \pm 0.2$ & $0.1 \pm 0.0$ & $0.2 \pm 0.1$ & $0.1 \pm 0.0$ \\
\hline KIM $185+$ Mg/EGTA & $9.4 \pm 0.6$ & $0.0 \pm 0.0$ & $0.1 \pm 0.0$ & $0.0 \pm 0.0$ \\
\hline & \multicolumn{2}{|c|}{ Mac-1 wild type } & \multicolumn{2}{|c|}{ Mac-1(S138P) } \\
\hline & & +LPM19c & & ${ }^{+}$LPM19c \\
\hline \multicolumn{5}{|l|}{ iC3b adhesion } \\
\hline None & $0.2 \pm 0.1$ & $0.1 \pm 0.0$ & $0.1 \pm 0.0$ & $0.1 \pm 0.0$ \\
\hline KIM 185 & $28.1 \pm 1.8$ & $0.1 \pm 0.0$ & $0.3 \pm 0.1$ & $0.1 \pm 0.0$ \\
\hline \multicolumn{5}{|l|}{ Denatured BSA adhesion } \\
\hline None & $0.7 \pm 0.1$ & $0.6 \pm 0.1$ & $0.5 \pm 0.2$ & $0.59 \pm 0.3$ \\
\hline KIM 185 & $22.3 \pm 1.5$ & $0.1 \pm 0.1$ & $0.5 \pm 0.0$ & $0.01 \pm 0.0$ \\
\hline
\end{tabular}

Percent cells adherent to the immobilized ligands are shown. Levels of LFA-1 and Mac-1 expression are similar to the profiles shown in Fig. 6 . ${ }^{A}$ MHM24 and LPM19c are specific MABs that block LFA-1- and Mac-1-mediated adhesion, respectively. ICAM, intercellular adhesion molecule.

infections with lesions extending into soft tissues, healing slowly, and leaving dysplastic scars. The severity of these episodes necessitated bone marrow transplantation in the autumn of 1997.

Expression of CD11/CD18 antigens on leukocytes. The chief characteristic of LAD-1 is the absence $(<1 \%)$ in severe cases or reduction (1\%-10\%) in moderate cases of $\beta 2$ integrin expression. LAD-1 heterozygotes have $\sim 50 \%$ expression of $\beta 2$ integrins and are clinically normal (9). We first used CD18 MAB L130 in whole blood to measure the patient's $\beta 2$ integrin levels compared with matched controls. The neutrophil $\beta 2$ integrin levels were 58\% (range $35 \%-87 \%$ ) of normal, and the lymphocyte levels were $65 \%$ (range 55\%-83\%) of normal controls $(n=5)$. The levels of $\beta 2$ expression varied considerably, undoubtedly due to the immune status of the patient, but the conclusion was that the levels of integrin expressed were similar to those of LAD-1 heterozygotes and should not have given rise to a severe deficiency in leukocyte function.

Expression of adhesion receptors on neutrophils. We next investigated expression of the individual $\beta 2$ integrins on the patient's resting neutrophils. The patient's levels of LFA-1 (CD11a/CD18) were equivalent to those of control neutrophils, and those of Mac-1 (CD11b/CD18) were $\sim 50 \%$ of those expressed by the control neutrophils (Fig. $1 a)$. This expression of $\beta 2$ integrins in the face of LAD- 1 symptoms suggested that there might be a deficiency in their ability to function. This was tested directly by inves- tigating the Mac-1-dependent adhesion of neutrophils to immobilized ligand fibrinogen. In the presence of formylmethionylleucylphenylalanine (FMLP), the patient's neutrophil Mac-1 displayed no evidence of adhesion to fibrinogen compared with a control (Fig. 1b), nor to $\mathrm{iC} 3 \mathrm{~b}$ (data not shown). In fact, background levels of adhesion of the patient's neutrophils were also well below those of the control neutrophils. Other stimulators of $\beta 2$ integrin adhesion, such as the $\beta 2$-activating MABs KIM 127 and $\operatorname{KIM} 185(27,28)$ and treatment with divalent cation $\mathrm{Mn}^{2+}(29)$, failed to induce Mac-1-specific adhesion of neutrophils (data not shown).

MAB 24 is specific for $\beta 2$ (CD11/CD18) integrins and reacts with an epitope that reports the activation of these integrins after exposure to extracellular cations $\mathrm{Mg}^{2+}$ or $\mathrm{Mn}^{2+}(7,29)$. On control neutrophils, the MAB 24 epitope was minimally present on resting cells, but expression was increased markedly in response to FMLP. In contrast, no MAB 24 epitope expression was seen in either resting or stimulated neutrophils from the patient (Fig. 1c). Therefore, in spite of the expression of adequate levels of the major neutrophil integrin Mac-1 (i.e., at the level similar to that found in heterozygote LAD-1 carriers), the patient's neutrophils exhibited a profound failure to function.

As expression of the neutrophil $\beta 2$ integrins was within expected range for normal function, it was possible that the cells were deficient in their ability to receive activating signals. Neutrophils were examined for other hallmarks 

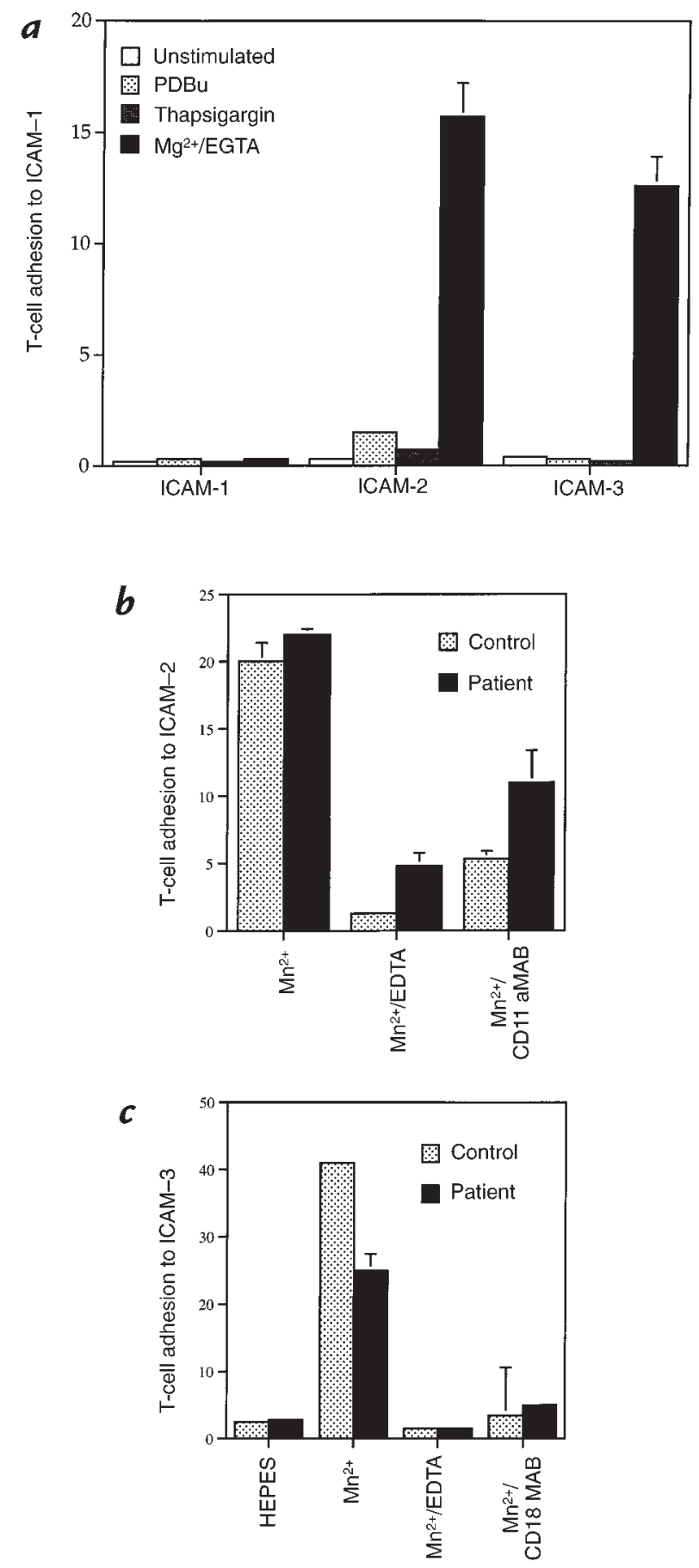

\section{Figure 3}

The distinctive recognition by patient T-cell LFA- 1 of ligands ICAM-1, ICAM-2, and ICAM-3 after various integrin-activating protocols. (a) Ability of patient $T$ cells to bind to immobilized ICAM-1, ICAM-2, and ICAM3 either as untreated cells (white bars) or after treatment with PDBu (dotted bars), $\mathrm{Ca}^{2+}$ mobilizer thapsigargin (gray bars), and $\mathrm{Mg}^{2+} / \mathrm{EGTA}$ (black bars). $\mathrm{Mg}^{2+} /$ EGTA is seen to induce patient T cells to bind to ICAM- 2 and ICAM-3 but not to ICAM-1. (b) The binding of patient T cells (black bars) and control T cells (dotted bars) to ICAM-2 after treatment with $0.5 \mathrm{mM}$ $\mathrm{Mn}^{2+}$ is prevented by chelation of divalent cations with EDTA and by CD11a function blocking MAB DF1524. (c) The binding of patient T cells (black bars) and control T cells (dotted bars) to ICAM-3 after $0.5 \mathrm{mM} \mathrm{Mn}{ }^{2+}$ is prevented by chelation of divalent cations with EDTA and by CD18 function blocking MAB 60.3. of activation such as the upregulation of expression of Mac-1 $(30,31)$. After stimulation with FMLP, there was a mean increase in Mac-1 of approximately twofold in both purified (Fig. 1c) and whole-blood neutrophils (data not shown) from control and patient. L-selectin loss, which is another feature of leukocyte activation, was comparably diminished by patient and control cells by FMLP (data not shown). The features indicate that the patient's neutrophils were able to respond to an exogenous activating stimulus in a normal manner.

Phenotypic analysis of the patient's T cells. It was possible that the functional lesion was restricted to neutrophils and that the $\beta 2$ integrins on other types of leukocytes might function normally. To test this possibility, we investigated the behavior of the $\beta 2$ integrin LFA- 1 and other characteristic T-cell phenotypic markers on the patient's T cells. A comparison of the fluorescence values shows LFA-1 expressed on the patient's T cells after culture to be a mean of $183.4 \pm 27.0(n=3)$ compared with $474.4 \pm 113.93(n=5)$ on control cells, indicating the level of patient LFA- 1 to be $\sim 40 \%$ of normal levels. In the samples illustrated in Table 1 , the two other $\beta 2$ integrins, Mac-1 and p150,95, were expressed at negligible levels on both patient and control T cells. MABs detecting other adhesion receptors, such as the $\beta 1$-integrin subunit (CD29), were present at normal levels on the LAD patient's T cells, as were the LFA-1 ligands ICAM-1 (CD54) and ICAM-3 (CD50). Other markers characteristic of the T cell, such as CD3, CD4, CD8, and CD45RO, were comparable between patient and control T cells (Table 1 ).

Functional analysis of the patient's T cells. The ability of the patient's T-cell LFA-1 to function was investigated by assessing binding activity to immobilized ligand. These $\mathrm{T}$ cells, in contrast to control $\mathrm{T}$ cells, could not be induced to bind to ICAM-1 after stimulation with a variety of agonists (Fig. 2). Agonists used for stimulation included those that mediate adhesion through intracellular signaling, such as $\mathrm{PDBu}, \mathrm{CD} 3$ triggering, or the $\mathrm{Ca}^{2+}$ mobilizer thapsigargin $(7,22)$, and those that induce adhesion from outside the cell by treatment with divalent cations $\mathrm{Mg}^{2+} /$ ethyleneglycol-bis $(\beta$ aminoethyl ether)- $N, N^{\prime}$-tetraacetic acid (EGTA) or $\mathrm{Mn}^{2+}$, as well as the $\beta 2$ integrin-activating MABs KIM 185 and KIM 127 (28). Adhesion of control T cells to ICAM-1 could be blocked in all cases by MABs specific for both LFA-1 (Fig. 2) and ICAM-1 (data not shown). These results demonstrate that LFA- 1 on the patient's T cells is not able to adhere to ICAM- 1 in either a constitutive or inducible fashion under a wide variety of adhesionactivating conditions.

Analysis of two other LFA-1 ligands, ICAM-2 and ICAM-3, showed that the patient's T cells could not be induced to adhere to them after PDBu and thapsigargin treatment (Fig. 3a) as did normal T cells (data not shown). However, they did bind to ICAM-2 and ICAM-3 after treatment with the divalent cations $\mathrm{Mg}^{2+} /$ EGTA (Fig. 3a) or $\mathrm{Mn}^{2+}$ (Fig. 3, b and c), which are considered to activate integrins from the cell exterior by directly altering their conformation (18). The adhesion was specific, as it was blocked by CD11a or CD18 MAB or by chelation of divalent cation with ethylenediaminetetraacetate (EDTA). 

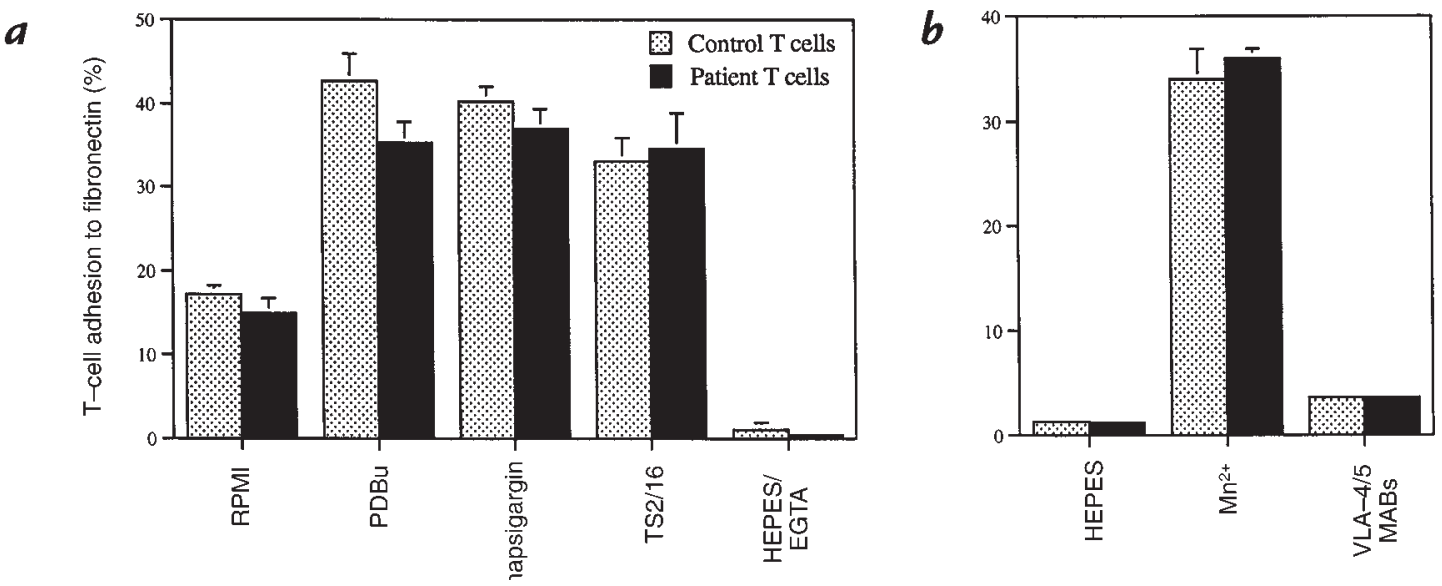

\section{Figure 4}

The ability of patient T cells and control T cells to adhere to immobilized fibronectin via $\beta 1$ integrins. (a) Control (dotted bars) and patient (black bars) T cells were untreated (RPMI), or treated with stimuli (PDBu, thapsigargin), by the $\beta 1$-activating MAB TS2/16 or by ablation of integrin-mediated adhesion with $1 \mathrm{mM}$ EDTA. ( $\boldsymbol{b})$ The increased adhesion of control and patient $T$ cells to fibronectin caused by divalent cation treatment with $0.5 \mathrm{mM}$ $\mathrm{Mn}^{2+}$ could be blocked by a combination of VLA-4 ( $\alpha 4 \beta 1$ )- and VLA-5 ( $\left.\alpha 5 \beta 1\right)$-specific MABs, HP1/2 and SAM-1, respectively. RPMI, Roswell Park Memorial Institute medium.

To determine whether there was a general defect in integrin function or something more specific to $\beta 2$ integrins, we examined the ability of $\beta 1$ receptors on $T$ cells to bind to the extracellular matrix molecule fibronectin. Both control and patient's $\mathrm{T}$ cells adhered comparably to fibronectin after stimulation with $\mathrm{PDBu}, \mathrm{Ca}^{2+}$ mobilizer thapsigargin, $\beta 1$ integrin-activating $\mathrm{MAB}$ TS2/16, and divalent cations $\mathrm{Mn}^{2+}$ (Fig. 4, $a$ and $b$ ) and $\mathrm{Mg}^{2+} /$ EGTA (data not shown). The adhesion was completely blocked with MABs to $\alpha 4$ (VLA-4/CD49d) and $\alpha 5$ (VLA$5 / \mathrm{CD} 49 \mathrm{e}$ ) integrins (Fig. $4 b$ ). Thus, the inability of patient $\mathrm{T}$ cells to bind to ICAM-1 does not reflect a general integrin deficiency, because VLA-4 ( $\alpha 4 \beta 1)$ and VLA-5 $(\alpha 5 \beta 1)$ integrins function normally.

Expression of integrin activation epitopes on T cells. Integrin activity was examined further by investigating induction of activation epitopes. MAB 24, which reports a state of activated $\beta 2$ integrin, was neither induced on the patient's T cells at $0.5 \mathrm{mM} \mathrm{Mn}^{2+}$ (Fig. 5) nor following titration of either $\mathrm{Mn}^{2+}$ or $\mathrm{Mg}^{2+} /$ EGTA up to $10 \mathrm{mM}$ divalent cation (data not shown). In contrast, these levels of cations induced MAB 24 expression on normal T cells. A $\beta 1$ activation epitope detected with MAB HUTS 21 was induced comparably by $0.5 \mathrm{mM} \mathrm{Mn}^{2+}$ treatment of both normal and patient's T cells (Fig. 5).

Identification of mutations $S 138 P$ and G273R in the patient's CD18 cDNA. Mutations were identified by sequencing clones of the $\beta 2$ cDNA fragments A (nt “-73" to "968”) and B (nt "860" to "2400") (Table 2). Nine fragment A clones were sequenced and two point mutations were identified. Six of nine clones had the nt change $T 412 C$, resulting in amino acid mutation $\mathrm{S} 138 \mathrm{P}$. The other three clones had the nt change G817A, resulting in the amino acid change G273R. Nine fragment $B$ clones were also sequenced; three clones had the nt change C1111A, and the other six, C1323T, with neither change affecting amino acids at $\mathrm{V} 367 \mathrm{~V}$ and V441V. One clone with each of the A frag- ments carrying the mutations, and each of the B fragments carrying the polymorphisms, was completely sequenced and no other mutation was found. It was not determined which polymorphism and point mutation were coassociated on the same allele. To verify these cDNA sequencing results, genomic DNA fragments containing the mutations were cloned and sequenced. Of the exon-5 clones, three were normal and three had the mutation S138P. Two exon-7 clones were normal and three had the mutation G273R. Thus, the patient is a compound heterozygote carrying the S138P and G273R mutations in his two CD18 alleles.

Expression of the two mutated CD18 alleles S138P and G273R on K562 cells. The expression of CD11/CD18 antigens on the patient's leukocytes is exceptionally high for patients with LAD-1. It was therefore reasonable to assume that one or potentially both mutations could support CD11/CD18 heterodimer formation. CD11 and CD18 cDNAs were electroporated into K562 cells, and expression was assayed after 24 hours using the CD18-specific MAB 1B4, which recognizes the $\beta 2$ subunit in heterodimeric form (32) (Law, S.K., unpublished data). It is clear that the S138P mutation can support the formation of LFA-1 and Mac-1 comparably to the wild-type CD18 subunit, whereas G273R cannot (Fig. 6). Identical results were obtained when the transfectants were tested with CD11a MAB MHM24, CD11b MAB 2LPM19c, or a second CD18 MAB H52, and similar results were also obtained after COS cell transfection (data not shown). The transfectants were tested in adhesion assays, using as immobilized ligand ICAM-1, -2 , and -3 for LFA -1 , and $\mathrm{iC} 3 \mathrm{~b}$ and denatured bovine serum albumin (BSA) for Mac-1. The wild-type transfectants gave positive adhesion in response to stimulants $\mathrm{Mg}^{2+}$ /EGTA and/or the activating CD18 MAB KIM 185, but the $\alpha$ subunits in combination with $\beta 2$ mutant S138P demonstrated no ability to adhere under any condition of stimulation (Table 3 ). 

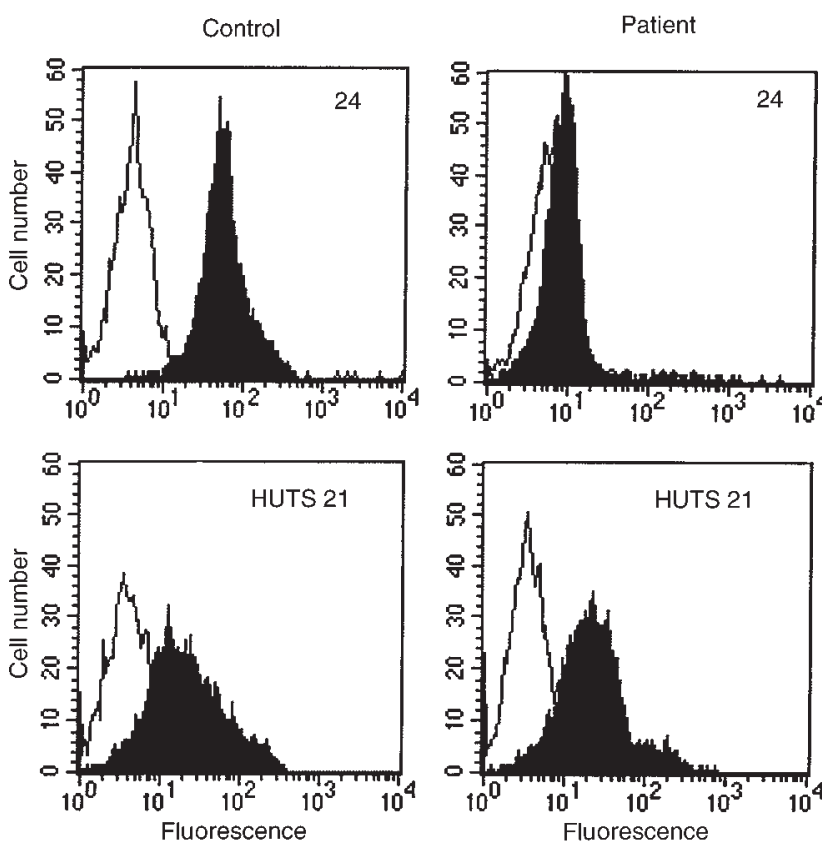

Figure 5

Expression patterns of $\beta 2$ - and $\beta 1$-integrin activation reporter epitopes on T cells detected by flow cytometry after exposure to $0.5 \mathrm{mM} \mathrm{Mn^{2+ }}$ (black) or without $\mathrm{Mn}^{2+}$ (white) at $37^{\circ} \mathrm{C}$ for $25 \mathrm{~min}$. Control, but not patient's, T cells express $\beta 2$ activation reporter epitope detected by MAB 24 (top panels). Conversely, the patient's T cells and control T cells express equivalent levels of the $\beta 1$ activation reporter epitope detected with MAB HUTS 21 (bottom panels).

\section{Discussion}

The LAD known as LAD- 1 is caused by reduced $\beta 2$ integrin expression on leukocytes. LAD-1 has been recognized as a neutrophil disorder because of recurrent lifethreatening infections principally due to the lack of the phagocytic receptor Mac-1 (9-11). We describe patient JT, who has all the clinical features of LAD-1 but has expression of the $\beta 2$ integrins at levels similar to those of LAD1 heterozygotes, who have $50 \%$ of normal expression but are clinically unaffected. Two novel mutations, S138P and G273R, were identified in the patient's CD18 alleles. We have shown that S138P can support expression of LFA- 1 and Mac- 1 on K562 transfectants but that the expressed integrin does not function. The G273R mutation supports neither expression nor function of LFA-1 or Mac-1. It is therefore likely that the CD11/CD18 antigens expressed on the patient's leukocytes contain the S138P mutation in the CD18 subunit and that the G273R mutation is responsible for the LAD-1 heterozygote-like levels of expression.

Neither the patient's neutrophils nor K562 transfectants expressing Mac-1(S138P) adhere to Mac-1 ligands fibrinogen and iC3b. However, the patient's T cells have limited CD11a/CD18-mediated adhesive properties. Whereas they do not adhere to ICAM-1 under any of the activation protocols tested, they can adhere to ICAM-2 and ICAM-3 when activated extracellularly with $\mathrm{Mg}^{2+} /$ EGTA and $\mathrm{Mn}^{2+}$. This result provides evidence that LFA-1 recognizes each ligand in a unique way and suggests the possibility that there could be a structural defect in the patient's LFA-1 that prevents interaction with ICAM-1 but allows some interaction with ICAM-2 and ICAM-3. There is previous evidence that LFA-1 interacts distinctively with its individual ligands. For example, CD11a MAB MEM-83 induced LFA-1 to selectively bind ICAM-1 but not to ICAM-3 $(33,34)$, and, conversely, two other CD11a MABs block binding of LFA-1 to ICAM-3 but not to ICAM-1 (34). The binding site for LFA-1 on ICAM-1 is located within the first two domains $(21,35)$; however, it appears that domain 1 of ICAM-3 is sufficient for LFA-1 binding (36). Electron microscopic evidence shows that for ICAM-3, domain 2 is less structurally dependent on domain 1 than for $\operatorname{ICAM}-1(35,37,38)$. Another difference is that ICAM-1 is present on the membrane as a dimer (39), whereas at least ICAM-2 appears to be a monomer (40). Finally, the fact that murine LFA- 1 can bind human ICAM-2 and ICAM-3, but not ICAM-1, implies that the first two ligands might have structural features in common not shared with ICAM-1 (41). Taken together, the implication of these observations is that the interaction of LFA-1 with ICAM-1 has special features distinct from that interaction with ICAM-2 and ICAM-3.

The patient's EBV-transformed B cells, and K562 transfectants expressing LFA-1(S138P), also failed to adhere to ICAM-1, but, unlike the patient's T cells, they cannot be promoted to adhere to ICAM-2 and ICAM-3 by divalent cation manipulation. This discrepancy may be due to the inability of the EBV-transformed B lymphocytes and the transfectants to respond to the full range of integrininducing signals. For example, adhesion to ICAM-2 or ICAM-3 of EBV-transformed B cells from a normal individual, and K562 cells expressing wild-type LFA-1, can only be consistently demonstrated with $\mathrm{Mg}^{2+} / \mathrm{EGTA}$ in addition to an activating MAB such as KIM 185. In comparison, either $\mathrm{Mg}^{2+}$ /EGTA or KIM 185 is sufficient to activate ICAM-1 adhesion (Table 3 and ref. 26). The

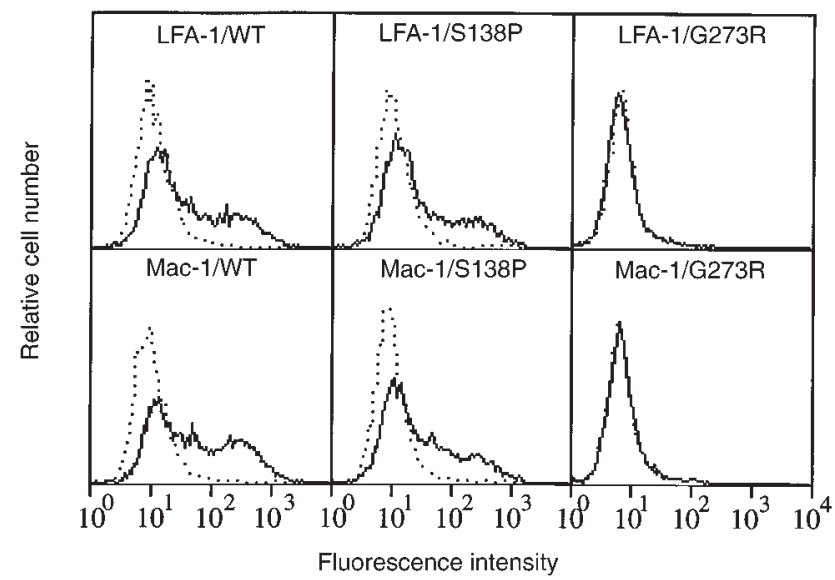

Figure 6

LFA-1 and Mac-1 expression profiles of K562 transfectants. Wild-type CD18 cDNA or CD18 cDNA carrying the S138P or G273R mutations were transfected into K562 together with CD11a cDNA (top panels) or CD11b cDNA (bottom panels). Expression of LFA-1 and Mac-1 was detected with the MAB 1B4 (solid lines). Background fluorescence was observed with MAB OX34 (dotted lines). 
patient's T cells had a completely normal ability to bind to fibronectin via the $\alpha 4 \beta 1$ (CD49d/CD29) and $\alpha 5 \beta 1$ (CD49e/CD29) integrins. As with other patients with LAD-1, the ability of leukocytes to bind to other integrins such as the fibronectin receptors makes possible lymphocyte responses, and, for this patient, the additional ability of recognizing ICAM- 2 and ICAM-3 may also have contributed to his survival into the midteen period.

The mutations found in the $\beta 2$ subunit of the patient have not been described previously. Both mutations lie in the putative I domain of the integrin $\beta 2$ subunit. A model of this region of the $\beta 2$-subunit I domain has two extra $\beta$ strands between $\beta$ strand D and helix 5 (42) when compared with a solved $\alpha$-subunit I-domain structure (43). The G273R mutation that leads to nonexpression of integrin is located in the loop between $\beta$ strand $D$ and the first extra $\beta$ strand. No function has yet been assigned to this loop, but it is of interest that G273R mutation affects heterodimer formation.

The S138P mutation is novel in that it gives rise to expression of $\alpha \beta$ heterodimer, but these integrins are without function. The S138P mutation is also novel in that it is the first reported natural mutation within the metal ion-dependent adhesion site (MIDAS) motif, which lies between the $\beta$ strand A and helix 1 of the Idomain model. The divalent cation binding MIDAS-like (DXSXS) motif was initially described in the I domain of the $\alpha$ subunit as the key $\mathrm{Mg}^{2+} / \mathrm{Mn}^{2+}$ binding site of the integrin on which ligand binding totally depends (43). It is also appreciated that $\beta$ subunits contain a MIDAS motif that binds cations and is involved in ligand binding (42-45). The patient's mutated S138P represents the second Ser in the DLSYS of the $\beta 2$ MIDAS motif. The importance of the conserved residues in DLSYS motif of $\beta 2$ was studied by mutagenesis in which the D134, S136, and S138 were replaced with Ala in three separate constructs (46). Whereas the D134A and S136A mutants were fully capable of forming LFA-1 and Mac-1, the resultant heterodimers were incapable of binding ICAM1 and $\mathrm{iC} 3 \mathrm{~b}$, respectively. Whether the mutants LFA$1(\mathrm{D} 134 \mathrm{~A})$ and LFA-1(S136A) can bind ICAM-2 and ICAM-3 was not addressed. The S138A mutant, in this same work, was reported to be defective in forming LFA1 and Mac-1 (46). However, the same mutation was reported to be competent in forming Mac-1 by another group. The Mac-1(S138A) was not adherent to $\mathrm{iC} 3 \mathrm{~b}$, denatured ovalbumin, and fibrinogen, but its binding to the neutrophil inhibitory factor was not impaired (47).

Another indicator of the status of integrin function is the expression of integrin "activation reporter" epitopes such as detected by MAB 24 for $\beta 2$ integrins (7). Expression of this epitope correlates with the increased ability of LFA- 1 to bind soluble ICAM- 1 , which is taken as a measure of high-affinity integrin $(7,18,48)$. Expression also correlates with an interdomain movement involving the $\alpha$ subunit I domain that occurs upon binding of $\mathrm{Mg}^{2+}(8)$. The lack of 24 epitope expression by the $\beta 2$ integrins on the patient's neutrophils and T cells confirmed that these integrins were not undergoing activation and may be deficient in tertiary structural changes necessary for full integrin function. Although $\mathrm{Mg}^{2+} /$ EGTA caused neither 24 epitope expression nor adhesion to ICAM-1, it did pro- mote adhesion to ICAM-2 and ICAM-3. The speculation here is that 24 epitope expression may mark an LFA- 1 conformation that is specifically required for ICAM-1 binding. In this regard, it is interesting that the mutagenesis of the $\beta 3$-subunit residue S123A, which corresponds to S138 of $\beta 2$, is associated with a lack of ability of the integrin $\alpha \operatorname{IIb} \beta 3$ to undergo conformational change (49).

In summary, we describe a patient expressing adequate levels of $\beta 2$ integrin but with failure of $\beta 2$-integrin function that has led to disease that is clinically indistinguishable from a moderately severe form of LAD-1. This patient differs from another recently described variant LAD-1 that has normal CD18 alleles but may have a signaling defect (50). Patient JT is, however, similar to a Glanzmann's thrombasthenia patient who has platelets with heterozygote-like expression of $\alpha \operatorname{IIb} \beta 3$. On one allele, this patient has a mutation giving rise to a truncated $\beta 3$ subunit, leading to faulty signaling and loss of function (51). Because patients with defects in integrin function may not be easily recognized by the usual characteristic of absent or low expression, it is presently unknown how common this variant type of lesion might be.

\section{Acknowledgments}

We are extremely grateful to patient JT and his family for their cooperation and support throughout this study and to Gareth Morgan, Mark Peters, and Karolina Kotowicz (Institute of Child Health) for bringing this patient to our attention, performing the platelet studies, and generating the EBV-transformed cell line (JT), respectively. We thank the following for generous gifts of monoclonal antibodies: Peter Beverley, Carlos Cabanas, David Flavell, and Martyn Robinson. Alison McDowall and Matthew Robinson (Imperial Cancer Research Fund, London, United Kingdom) provided extremely helpful comments on this manuscript.

1. Butcher, E.C., and Picker, J.L. 1996. Lymphocyte homing and homeostasis. Science. 272:60-66.

2. Brown, E.J. 1997. Adhesive interactions in the immune system. Trends Cell Biol. 7:289-295.

3. Bachmann, M.F., et al. 1997. Distinct roles for LFA-1 and CD28 during activation of naive T cells: adhesion versus costimulation. Immunity. 7:549-557.

4. Brown, E.J. 1991. Complement receptors and phagocytosis. Curr. Opin. Immunol. 3:76-82.

5. Ross, G.D., Reed, W., Dalzell, J.G., Becker, S.E., and Hogg, N. 1992. Macrophage cytoskeleton association with CR3 and CR4 regulates receptor mobility and phagocytosis of iC3b-opsonized erythrocytes. J. Leukoc. Biol. 51:109-117.

6. Diamond, M.S., and Springer, T.A. 1994. The dynamic regulation of integrin adhesiveness. Curr. Biol. 4:506-517.

7. Stewart, M., and Hogg, N. 1996. Regulation of leukocyte integrin function: affinity vs. avidity. J. Cell. Biochem. 61:554-561.

8. McDowall, A., et al. 1998. The I domain of integrin leukocyte functionassociated antigen-1 is involved in a conformational change leading to high affinity binding to ligand intercellular adhesion molecule 1 (ICAM1). J. Biol. Chem. 273:27396-27403.

9. Anderson, D.C., et al. 1985. The severe and moderate phenotypes of heritable Mac-1, LFA-1 deficiency: their quantitative definition and relation to leukocyte dysfunction and clinical features. J. Infect. Dis. 152:669-689.

10. Anderson, D.C., and Springer, T.A. 1987. Leukocyte adhesion deficiency: an inherited defect in the Mac-1, LFA-1 and p150,95 glycoproteins. Ann. Rev. Med. 38:175-187.

11. Arnaout, M.A., and Michishita, M. 1993. Genetic abnormalities in leukocyte adhesion molecule deficiency. In New concepts in immunodeficiency diseases. S. Gupta and C. Griscelli, editors. J. Wiley \& Sons. New York, NY. 190-200.

12. Fischer, A., et al. 1983. Bone marrow transplantation for inborn error of phagocytic cells associated with defective adherence, chemotaxis and oxidative response during opsonised particle phagocytosis. Lancet. 2:473-476.

13. Dransfield, I., and Hogg, N. 1989. Regulated expression of $\mathrm{Mg}^{2+}$ binding 
epitope on leukocyte integrin $\alpha$ subunits. EMBO J. 8:3759-3765.

14. Luque, A., et al. 1996. Activated conformations of very late activation integrins detected by a group of antibodies (HUTS) specific for a novel regulatory region (355-425) of the common $\beta 1$ chain. J. Biol. Chem. 271:11067-11075.

15. Dooley, D.C., Simpson, J.F., and Meryman, H.T. 1982. Isolation of large numbers of fully viable human neutrophils: a preparative technique using Percoll density gradient centrifugation. Exp. Hematol. 10:591-599.

16. Dransfield, I., Cabañas, C., Craig, A., and Hogg, N. 1992. Divalent cation regulation of the function of the leukocyte integrin LFA-1. J. Cell Biol. 116:219-226.

17. Newton, R.A., and Hogg, N. 1998. The human S100 protein MRP-14 is a novel activator of the beta 2 integrin Mac- 1 on neutrophils. J. Immunol. 160:1427-1435.

18. Stewart, M.P., Cabañas, C., and Hogg, N. 1996. T cell adhesion to intercellular adhesion molecule-1 (ICAM-1) is controlled by cell spreading and the activation of integrin LFA-1. J. Immunol. 156:1810-1817.

19. Klein, N.J., et al. 1996. The influence of capsulation and lipopolysaccharide structure on neutrophil adhesion molecule expression and endothelial injury by Neisseria meningitidis. J. Infect Dis. 173:172-179.

20. Vaporciyan, A.A., et al. 1993. Involvement of platelet-endothelial cell adhesion molecule-1 in neutrophil recruitment in vivo. Science. 262:1580-1582.

21. Berendt, A. R., et al. 1992. The binding site on ICAM-1 for Plasmodium falciparum-infected erythrocytes overlaps, but is distinct from, the LFA-1binding site. Cell. 68:71-81.

22. Stewart, M.P., McDowall, A., and Hogg, N. 1998. LFA-1 mediated adhesion is regulated by cytoskeletal restraint and by a $\mathrm{Ca}^{2+}$-dependent protease, calpain. J. Cell Biol. 140:699-707.

23. Bell, G.I., Karam, J.H., and Rutter, W.J. 1981. Polymorphic DNA regions adjacent to the $5^{\prime}$ end of the human insulin gene. Proc. Natl. Acad. Sci. USA. 78:5759-5763.

24. Weitzman, J.B., Wells, C.E., Wright, A.H., Clark, P.A., and Law, S.K.A. 1991. The gene organisation of the human $\beta 2$ integrin subunit (CD18). FEBS Lett. 294:97-103.

25. Wright, A.H., et al. 1995. Molecular characterization of leukocyte adhesion deficiency in six patients. Eur. J. Immunol. 25:717-722.

26. Al-Shamkhani, A., and Law, S.K.A. 1998. Expression of the H52 epitope on the $\beta 2$ subunit is dependent on its interaction with the subunits of the leukocyte integrins LFA-1, Mac-1 and p150,95 and the presence of $\mathrm{Ca}^{2+}$. Eur. J. Immunol. 28:3291-3300.

27. Andrew, D., et al. 1993. KIM-185, a monoclonal antibody to CD18 which induces a change in the conformation of CD18 and promotes both LFA1 and CR3-dependent adhesion. Eur. J. Immunol. 23:2217-2222.

28. Ortlepp, S., Stephens, P. E., Hogg, N., Figdor, C.G., and Robinson, M.K. 1995. Antibodies that activate $\beta 2$ integrins can generate different ligand binding sites. Eur. J. Immunol. 25:637-643.

29. Dransfield, I., Cabañas, C., Barrett, J., and Hogg, N. 1992. Interaction of leukocyte integrins with ligand is necessary but not sufficient for function. J. Cell Biol. 116:1527-1535.

30. Todd, R.F., et al.1984. Subcellular localization of the large subunit of Mo1 (Mo1 $\alpha$ : formerly gp110), a surface glycoprotein associated with neutrophil adhesion. J. Clin. Invest. 74:1280-1290.

31. Springer, T.A., Thompson, W.S., Miller, L.J., Schmalstieg, F.C., and Anderson, F.C. 1984. Inherited deficiency of the Mac-1, LFA-1, p150,95 glycoprotein family and its molecular basis. J. Exp. Med. 137:15-27.
32. Wright, S.D., et al. 1983. Identification of the C3bi receptor of human monocytes and macrophages by using monoclonal antibodies. Proc. Natl. Acad. Sci. USA. 80:5699-5703.

33. Landis, R.C., Bennett, R.I., and Hogg, N. 1993. A novel LFA-1 activation epitope maps to the I domain. J. Cell Biol. 120:1519-1527.

34. Landis, R.C., et al. 1994. Involvement of the "I" domain of LFA-1 in selective binding to ligands ICAM-1 and ICAM-3. J. Cell Biol. 126:529-537.

35. Staunton, D.E., Dustin, M.L., Erickson, H.P., and Springer, T.A. 1990. The arrangement of the immunoglobulin-like domains of ICAM-1 and the binding sites for LFA-1 and rhinovirus. Cell. 61:243-254.

36. Klickstein, L.B., York, M.R., de Fougerolles, A.R., and Springer, T.A. 1996. Localization of the binding site on intercellular adhesion molecule-3 (ICAM-3) for lymphocyte function-associated antigen-1 (LFA-1). J. Biol. Chem. 271:23920-23927.

37. Kirchhausen, T., Staunton, D.E., and Springer, T.A. 1993. Location of the domains of ICAM-1 by immunolabeling and single-molecule electron microscopy. J. Leukoc. Biol. 53:342-346.

38. Sadhu, S., et al. 1994. LFA-1 binding site in ICAM-3 contains a conserved motif and non-contiguous amino acids. Cell Adhes. Commun. 2:429-440.

39. Reilly, P.L., et al. 1995. The native structure of intercellular adhesion molecule-1 (ICAM) is a dimer. J. Immunol. 155:529-532.

40. Miller, J., et al. 1995. Intercellular Adhesion Molecule-1 dimerization and its consequences for adhesion mediated by lymphocyte function associated-1. J. Exp. Med. 182:1231-1241.

41. Driessens, M.H., Van Hulten, P., Zuurbier, A, La Riviere, G, and Roos, E. 1996. Inhibition and stimulation of LFA-1 and Mac-1 functions by antibodies against murine CD18. Evidence that the LFA-1 binding sites for ICAM-1, -2 and -3 are distinct. J. Leukoc. Biol. 60:758-765.

42. Tuckwell, D.S., and Humphries, J.M. 1997. A structure prediction for the ligand-binding region of the integrin beta subunit: evidence for the presence of a von Willebrand factor A domain. FEBS Lett. 400:297-303.

43. Lee, J.-O., Rieu, P., Arnaout, M.A., and Liddington, R. 1995. Crystal structure of the A-domain from the $\alpha$-subunit of integrin CR3 (CD11b/CD18). Cell. 80:631-638.

44. Puzon-McLaughlin, W., and Takada, Y. 1996. Critical residues for ligand binding in an I domain-like structure of the integrin $\beta 1$ subunit. J. Biol. Chem. 271:20438-20443.

45. Tozer, E.C., et al. 1996. Ligand binding to integrin $\alpha_{\mathrm{II}} \beta_{3}$ is dependent on a MIDAS-like domain in the $\beta_{3}$ subunit. J. Biol. Chem. 271:21978-21984.

46. Bajt, M.L., Goodman, T., and McGuire, S.L. 1995. $\beta_{2}$ (CD18) mutations abolish ligand recognition by I domain integrins LFA-1 $\left(\alpha_{\mathrm{L}} \beta_{2}\right.$, CD11a/CD18) and MAC-1 ( $\alpha_{\mathrm{M}} \beta_{2}$, CD11b/CD18). J. Biol. Chem. 270:94-98.

47. Zhang, L., and Plow, E.F. 1996. Overlapping, but not identical, sites are involved in the recognition of C3bi, neutrophil inhibitory factor, and adhesive ligands by the $\alpha \mathrm{M} \beta 2$ integrin. J. Biol. Chem. 271:18211-18216.

48. Cabañas, C., and Hogg, N. 1993. Ligand intercellular adhesion molecule 1 has a necessary role in the activation of integrin lymphocyte functionassociated molecule 1. Proc. Natl. Acad. Sci. USA. 90:5838-5842.

49. Bajt, M.L., and Loftus, J.C. 1994. Mutation of a ligand binding domain of $\beta_{3}$ integrin. J. Biol. Chem. 269:20913-20919.

50. Kuijpers, T.W., et al. 1997. Leukocyte adhesion deficiency type 1 (LAD1)/variant. J. Clin. Invest. 100:1725-1733

51. Wang, R., Shattil, S. J., Ambruso, D.R., and Newman, P.J. 1997. Truncation of the cytoplasmic domain of $\beta 3$ in a variant form of Glanzmann thrombasthenia abrogates signalling through the integrin $\alpha \mathrm{IIb} \beta 3$ complex. J. Clin. Invest. 100:2393-2403. 